\title{
Extracts for Analysis of DNA Replication in a Nucleus-Free System
}

\author{
Justin Sparks ${ }^{1}$ and Johannes C. Walter ${ }^{1,2,3}$ \\ ${ }^{1}$ Department of Biological Chemistry and Molecular Pharmacology, Harvard Medical School, Boston, \\ Massachusetts 02115; ${ }^{2}$ Howard Hughes Medical Institute, Department of Biological Chemistry and Molecular \\ Pharmacology, Harvard Medical School, Boston, Massachusetts 02115
}

Frog egg extracts represent a powerful approach with which to dissect molecular mechanisms of vertebrate DNA replication and repair. In the classical approach, sperm chromatin is added to a crude egg lysate to form replication-competent nuclei. We subsequently described a procedure that bypasses the requirement for nuclear assembly in DNA replication. In this method, DNA is first added to a high-speed supernatant (HSS) of egg lysate, which mimics the $\mathrm{G}_{1}$ phase of the cell cycle in that it supports replication licensing. Subsequent addition of a concentrated nucleoplasmic extract (NPE) leads to replication initiation followed by a single complete round of DNA replication. The advantage of the nucleus-free system is that it supports efficient replication of model DNA templates such as plasmids and lambda DNA that can be modified with specific features such as LacI arrays, DNA protein cross-links, or DNA interstrand cross-links. Here, we describe our current protocol for preparation of HSS and NPE. Methods for their use in DNA replication and repair are described elsewhere.

It is essential that you consult the appropriate Material Safety Data Sheets and your institution's Environmental Health and Safety Office for proper handling of equipment and hazardous materials used in this protocol.

RECIPES: Please see the end of this protocol for recipes indicated by $<R>$. Additional recipes can be found online at http://cshprotocols.cshlp.org/site/recipes.

\section{Reagents}

Adenosine 5'-triphosphate disodium salt hydrate (0.2 M; Sigma-Aldrich A5394)

Dissolve in sterile water and adjust to $\mathrm{pH} \sim 7$ with $10 \mathrm{M} \mathrm{NaOH}$ using $\mathrm{pH}$ indicator paper. Store aliquots at $-20^{\circ} \mathrm{C}$.

Aprotinin/leupeptin stock solution (10 mg/mL each; Roche 11583794001, 11529048001)

Dissolve in filter-sterilized water, and store aliquots at $-80^{\circ} \mathrm{C}$.

Benzocaine $(10 \%(\mathrm{w} / \mathrm{v})$ stock solution in ethanol)

Stable for 6 mo at room temperature.

Creatine phosphokinase solution $<\mathrm{R}>$

\footnotetext{
${ }^{3}$ Correspondence: johannes_walter@hms.harvard.edu From the Xenopus collection, edited by Hazel L. Sive.

(C) 2019 Cold Spring Harbor Laboratory Press

Cite this protocol as Cold Spring Harb Protoc; doi:10.1101/pdb.prot097154
} 
Cycloheximide (10 mg/mL; Calbiochem 239763)

Make fresh by dissolving in filter-sterilized water.

Cytochalasin B (5 mg/mL; Sigma-Aldrich C6762)

Dissolve in DMSO, and store aliquots at $-20^{\circ} \mathrm{C}$.

Dejelly solution ( $1 \mathrm{~L}$ for HSS; $2 \mathrm{~L}$ for NPE) $<\mathrm{R}>$

Dithiothreitol (DTT; 1 M; Bio-Rad 161-0611)

Dissolve in filter-sterilized water, and store aliquots at $-20^{\circ} \mathrm{C}$.

ELB-sucrose (1 L for HSS; 2 L for NPE) $<$ R $>$

Ethanol (70\%)

Hoechst stock solution $<\mathrm{R}>$

Hormones for inducing ovulation (see Lebofsky et al. 2009)

Ice

Liquid nitrogen

Marc's modified Ringer's (MMR) for Xenopus $(20 \times)<\mathrm{R}>$

MMR (0.5×; 2 L for HSS; 4 L for NPE)

Dilute from $20 \times M M R$ with $\mathrm{dH}_{2} \mathrm{O}$; make fresh on the day of extract preparation.

Mature female Xenopus laevis frogs (six for HSS; 20 for NPE)

Mature male Xenopus laevis frogs (six to eight)

$\mathrm{NaCl}$ (100 mM; 15 L for HSS; 50 L for NPE)

Nocodazole (5 mg/mL; Sigma-Aldrich M14104)

Dissolve in DMSO. Store aliquots at $-20^{\circ} \mathrm{C}$.

Phosphocreatine disodium salt (1 M, Sigma-Aldrich P7936)

Dissolve in $10 \mathrm{~mm}$ sodium phosphate $\mathrm{pH}$ 7. Store aliquots at $-20^{\circ} \mathrm{C}$.

Sucrose buffers for preparation of demembranated sperm chromatin $<\mathrm{R}>$

It is important to make the sucrose solutions well before beginning the protocol as the sucrose can take an hour or more to dissolve.

Triton X-100 (20\% stock solution in sterile water)

Equipment

Aspiration setup

Benchtop centrifuge with swinging-bucket rotor, such as IEC Centra CL2, or equivalent, with adapters

to hold 1.5-mL microcentrifuge tubes and Falcon 2059 15-mL tubes

Centrifuge (Sorvall Lynx 4000) and swinging-bucket rotor TH13-6X50 or equivalent, with adapters to hold Falcon 2059 15-mL tubes

Conical tubes with screw caps ( 15 and $50 \mathrm{~mL}$ )

Coverslips

Dissection equipment (i.e., forceps, scissors, pithing needle)

Gel-loading tips

Glass beakers (100-mL; 6)

Glass beakers (2-L)

Glass test tubes $(13 \times 100$ mm; Kimble Glass Inc. 73500 13100)

Hemocytometer

Ice buckets, $10 \mathrm{~L}$

Microcentrifuge tubes ( 1.5 and $2 \mathrm{~mL}$ )

Microscope, epifluorescent (e.g., an Eclipse E600POL [Nikon])

Microscope slides

Needles (18-gauge)

Paper towels 
J. Sparks and J.C. Walter

Pasteur pipettes, glass

Petri dishes

Plastic transfer pipettes

Polypropylene tubes (15-mL; Falcon 2059 tubes or similar)

Razor blades (2-3)

Rotating wheel, end-over-end

Spray bottle for ethanol

Ultracentrifuge, such as Optima Max-E (Beckman), with swinging-bucket rotor, such as the TLS-55

(Beckman), or equivalent

It is important that the ultracentrifuge can be chilled and the configuration can reach and withstand speeds of up to $260,000 \mathrm{~g}$.

Ultracentrifuge tubes (2.5-mL; thick-walled; Beckman 343778)

Use for NPE if yield is $<1.5 \mathrm{~mL}$.

Ultracentrifuge tubes (2.5-mL; thin-walled and clear; Beckman 347356)

Use for sperm chromatin and HSS. Use also for NPE if yield is greater than $1.5 \mathrm{~mL}$.

Vortex

Waste beaker (4-L)

\section{METHOD}

紧

Preparation of Demembranated Sperm Chromatin

All steps are performed at room temperature unless otherwise stated.

1. In a $2 \mathrm{~L}$ beaker, dilute $6 \mathrm{~mL}$ of $10 \%$ benzocaine in $800 \mathrm{~mL}$ of water $(0.075 \%)$.

2. Euthanize a male frog by placing it in the benzocaine solution for $\sim 6 \mathrm{~min}$ or until it no longer rights itself when turned over and lacks a sucking reflex (frog does not suck on gloved finger placed in its mouth).

3. Remove frog from benzocaine and ensure euthanasia by pithing the frog's spinal cord at the junction with its skull.

4. Recover the testes by first making an incision across the stomach and continuing up both sides of the frog's abdomen. The testes are attached to the intestine wall. Xenopus testes are white or cream in color, bean shaped, and $\sim 5-8 \mathrm{~mm}$ in length and 3-4 $\mathrm{mm}$ in width. Using scissors, cut the testes away from the connective tissue and place them on a dry paper towel.

Once the testes are removed, place the next male frog in the benzocaine solution.

5. While waiting for the next frog to be euthanized, blot the blood from the testes with a dry paper towel and remove excess connective tissue and blood vessels on the surface of the testes. It is not essential to remove all excess tissue at this point.

6. Place clean testes in a Petri dish with $2-3 \mathrm{~mL}$ of buffer \#1 (Sucrose buffers for preparation of demembranated sperm chromatin).

7. Start dissection of next frog.

8. Once testes have been recovered from all six frogs, cleaned, and collected in the petri dish containing buffer \#1, remove the testes from the petri dish and reclean them by removing any leftover connective tissue or blood with forceps and scissors. Place the clean testes in a new Petri dish with $1 \mathrm{~mL}$ of buffer \#1. At this step, it is essential to remove all visible connective tissue and blood cells.

Adding more buffer will make the chopping in the next step less efficient. 
9. Mince the testes into tiny pieces by extensive chopping with a razor blade for $10 \mathrm{~min}$. Change blades every $3-4 \mathrm{~min}$.

10. Transfer the minced testes into a $15 \mathrm{~mL}$ screw cap conical tube with a p1000 tip. If there are pieces of testes too big to be removed with a p1000 tip, the testes are not minced enough.

11. Rinse the petri dish with small volumes of buffer $\# 1$ and combine the buffer with the minced testes to a final volume of $\sim 6 \mathrm{~mL}$.

Use the same p1000 tip to avoid losing material.

12. Vortex the tube vigorously for $1 \mathrm{~min}$ and pellet the large pieces of tissue by centrifugation for $10 \mathrm{sec}$ at $200 \mathrm{~g}$ at room temperature in a benchtop centrifuge with a swinging-bucket rotor, such as the IEC Centra CL2 or equivalent, with adapters to hold $15 \mathrm{~mL}$ screw cap conical tubes.

13. Transfer the supernatant (cloudy) to a $15 \mathrm{~mL}$ Falcon 2059 tube at room temperature.

14. Add $2 \mathrm{~mL}$ of buffer \#1 to the pellet from Step 12 and vortex for $1 \mathrm{~min}$.

15. Centrifuge the tube for $15 \mathrm{sec}$ at $200 \mathrm{~g}$ at room temperature in the same centrifuge used in Step 12. Combine the supernatant with the supernatant from Step 13. Repeat Steps 13-14 two to three times until the supernatant is no longer cloudy.

16. Centrifuge the combined supernatants for $50 \mathrm{sec}$ at $380 \mathrm{~g}$ at room temperature in the same centrifuge used in Step 12. Transfer the supernatant to a new $15 \mathrm{~mL}$ Falcon 2059 tube using a p1000 tip. Be careful to avoid transfer of the pelleted tissue in this step. Remaining supernatant will be recovered in Step 17.

17. Add $12 \mathrm{~mL}$ of buffer \#1 to the pellet from Step 16. Vortex for $1 \mathrm{~min}$ and centrifuge for $50 \mathrm{sec}$ at $380 \mathrm{~g}$ at room temperature in the same centrifuge used in Step 12. Keep the supernatant and transfer it to a new $15 \mathrm{~mL}$ Falcon 2059 tube. Be careful to avoid transfer of the pelleted tissue in this step.

18. Centrifuge both 2059 tubes to pellet the sperm for $15 \mathrm{~min}$ at $2600 \mathrm{~g}$ at $4^{\circ} \mathrm{C}$ in a Sorvall Lynx 4000 centrifuge and swinging-bucket rotor TH13-6X50 (or equivalent), with adapters to hold Falcon $205915-\mathrm{mL}$ tubes. After centrifugation, there should be a visible gray pellet in the tubes. This pellet contains the sperm.

From now on, the sperm should be kept on ice.

19. During the above centrifugation, prepare sucrose step gradients in four $2.5 \mathrm{~mL}$ thin-walled ultracentrifuge tubes. Pour gradients on ice with a cut p1000 tip. In each tube, underlay $1.7 \mathrm{~mL}$ of buffer \#2 (2.3 M sucrose) with $0.25 \mathrm{~mL}$ of buffer \#3 (2.5 M sucrose). First add $1.7 \mathrm{~mL}$ of buffer \#2 to the tubes and then underlay with buffer \#3 by positioning the pipette tip at the bottom of the tube and slowly expelling buffer \#3 under buffer \#2.

20. Following centrifugation (Step 18), discard the supernatant and thoroughly resuspend the sperm pellet in a total of $1.2 \mathrm{~mL}$ ( $600 \mu \mathrm{L}$ in each tube) of buffer \#4 (2 M sucrose) using a P1000 tip, while keeping the solution on ice.

It is essential to fully resuspend the sperm without leaving any clumps. This can take up to $15 \mathrm{~min}$.

21. Overlay each of the four sucrose step gradients with the sperm preparation $(0.2-0.4 \mathrm{~mL} /$ gradient $)$. Thoroughly mix the interface between the sperm and the buffer \#2 with a sealed p200 tip (smash the tip with forceps) by alternately pushing the tip into the sperm and sucrose gradient and stirring the tip in the sperm layer until the sperm layer increases to about $2.5 \times$ its original depth.

22. Centrifuge the sucrose gradients in an Optima Max-E ultracentrifuge (Beckman) with a swinging-bucket rotor, such as the TLS-55 (Beckman), or equivalent for $45 \mathrm{~min}$ at $93,000 \mathrm{~g}$ at $2^{\circ} \mathrm{C}$.

Red blood cells should band on the top of the $2.3 \mathrm{~m}$ sucrose layer. The sperm will form a pellet on the bottom of the tube. If there is still a cloudy layer above the red blood cells, remix the upper layers with a sealed p200 tip and centrifuge for another $20 \mathrm{~min}$. 
23. Aspirate away the top half of the gradient containing the red blood cells. Recover the rest of the gradient with a p1000 tip and transfer it to a $15 \mathrm{~mL} 2059$ Falcon tube. The bottom half of the gradient may contain sperm.

24. Resuspend each sperm pellet with $300 \mu \mathrm{L}$ of buffer $\# 1$ by pipetting up and down with a p1000 tip (avoid the upper wall of the tube to avoid contamination by red blood cells). Transfer the sperm to the $15 \mathrm{~mL} 2059$ Falcon tube from Step 23.

25. Dilute the sperm to a final volume of $12 \mathrm{~mL}$ with buffer \#1 and mix by inversion. Pellet the sperm by centrifugation for $15 \mathrm{~min}$ at $3000 \mathrm{~g}$ at $4^{\circ} \mathrm{C}$ in a Sorvall Lynx 4000 centrifuge and swingingbucket rotor TH13-6X50, with adapters to hold Falcon 2059 15-mL tubes.

26. Remove the supernatant and resuspend the sperm pellet in $0.5 \mathrm{~mL}$ of buffer \#1 plus $10 \mu \mathrm{g} / \mathrm{mL}$ aprotinin/leupeptin and $1 \mathrm{~mm}$ DTT. Transfer sperm to a $2 \mathrm{~mL}$ microfuge tube.

27. Adjust the volume to $1.66 \mathrm{~mL}$ with buffer \#1 plus aprotinin/leupeptin $(10 \mu \mathrm{g} / \mathrm{mL})$ and DTT (1 mM). Mix thoroughly.

28. Add $34 \mu \mathrm{L}$ of $20 \%$ Triton $\mathrm{x}-100$ for a final concentration of $0.4 \%$ TX-100. Gently mix by inversion.

29. Incubate on an end-over-end rotating wheel for $45 \mathrm{~min}$ at $4^{\circ} \mathrm{C}$.

30. Prepare four $1.5 \mathrm{~mL}$ microfuge tubes each containing $0.5 \mathrm{~mL}$ buffer \#5 plus $3.0 \%$ BSA, aprotinin/ leupeptin $(10 \mu \mathrm{g} / \mathrm{mL})$, and DTT $(1 \mathrm{~mm})$.

31. After the $45 \mathrm{~min}$ incubation, overlay each sucrose cushion from Step 30 with $1 / 4$ of the sperm preparation.

32. Centrifuge the tubes for $10 \mathrm{~min}$ at $750 \mathrm{~g}$ at room temperature in a benchtop centrifuge with swinging-bucket rotor, such as IEC Centra CL2 or equivalent, with adapters to hold $1.5 \mathrm{~mL}$ microcentrifuge tubes. Place tubes on ice between spins.

33. Remove and discard the supernatant by aspiration and resuspend each pellet in $0.2 \mathrm{~mL}$ of buffer \#6 plus 3.0\% BSA, aprotinin/leupeptin $(10 \mu \mathrm{g} / \mathrm{mL})$, and DTT (1 mM). It is essential to avoid the sides of the tubes containing residual Triton X-100.

Make sure to resuspend the sperm pellet very well in the tube.

34. Transfer the sperm chromatin to four new $1.5 \mathrm{~mL}$ microcentrifuge tubes and dilute to $0.7 \mathrm{~mL}$ with buffer \#6 plus $3.0 \%$ BSA, aprotinin/leupeptin $(10 \mu \mathrm{g} / \mathrm{mL})$, and DTT (1 mM). Mix and centrifuge for $5 \mathrm{~min}$ at $750 \mathrm{~g}$ at room temperature in the same centrifuge used in Step 32.

35. Repeat Steps 33-34.

36. Remove the supernatant. Resuspend each sperm chromatin pellet in $0.2 \mathrm{~mL}$ of buffer \#6 plus $3.0 \% \mathrm{BSA}$, aprotinin/leupeptin $(10 \mu \mathrm{g} / \mathrm{mL})$, and DTT $(1 \mathrm{~mm})$. Combine and adjust the volume to around $1-1.5 \mathrm{~mL}$ with the same buffer. Store on ice.

37. To determine the sperm concentration, mix $3 \mu \mathrm{L}$ of the sperm prep with $30 \mu \mathrm{L}$ Hoechst solution and $67 \mu \mathrm{L}$ of water to a final volume of $100 \mu \mathrm{L}$. Count the number of sperm using a hemocytometer with the UV/DAPI channel on an epifluorescent microscope and calculate the concentration of the undiluted preparation.

The sperm chromatin sediment quickly. Therefore, it is essential to mix the sperm by inverting the tube just prior to taking a sample for counting as well as prior to distributing the sperm into the aliquots.

38. Dilute the sperm to a final concentration of $220,000 / \mu \mathrm{L}$ using buffer \#6 plus $3.0 \%$ BSA, aprotinin/ leupeptin $(10 \mu \mathrm{g} / \mathrm{mL})$, and DTT $(1 \mathrm{~mm})$, and snap freeze in liquid nitrogen in $90 \mu \mathrm{L}$ aliquots in $1.5 \mathrm{~mL}$ microfuge tubes. Store at $-80^{\circ} \mathrm{C}$. Alternatively, do not dilute the sperm and aliquot sperm in an appropriate volume to yield aliquots of 19.8 million sperm chromatin/aliquot. Snap freeze in liquid nitrogen in $1.5 \mathrm{~mL}$ microfuge tubes. Store at $-80^{\circ} \mathrm{C}$.

The important factor in aliquotting is not the concentration but the number of sperm chromatin per aliquot that will be used for nuclear assembly. 


\section{Preparation of LSS (Low-Speed Supernatant) Extract}

For preparation of a high-speed supernatant (HSS), we harvest unfertilized eggs from six female frogs. The unfertilized eggs are arrested in metaphase II of meiosis. cytostatic factor (CSF) blocks cell cycle progression in the unfertilized eggs (Lohka et al. 1988). The eggs are first crushed at low centrifugal force which allows for release of intracellular $\mathrm{Ca}^{2+}$ to promote MPF destruction, facilitating entry into interphase (Murray et al. 1989), and making low-speed supernatant (LSS). The LSS is recentrifuged at high centrifugal force to make HSS.

39. Induce ovulation in six female Xenopus laevis frogs according to standard protocols (Lebofsky et al. 2009). Collect eggs from each frog separately into $2.5 \mathrm{~L}$ of $100 \mathrm{~mm} \mathrm{NaCl}$.

40. Prepare $1 \mathrm{~L}$ Dejelly solution, $2 \mathrm{~L}$ 0.5× MMR, and $1 \mathrm{~L}$ of ELB-sucrose. Prepare MMR and ELBsucrose in graduated cylinders for easy pouring. Prepare $1 \mathrm{~mL}$ of $10 \mathrm{mg} / \mathrm{mL}$ cycloheximide. Ensure the swinging-bucket rotor is at room temperature for egg crushing.

41. Pour the majority of the $100 \mathrm{~mm} \mathrm{NaCl}$ out of the egg laying bucket. Gently collect eggs from each frog into a separate $100 \mathrm{~mL}$ beaker, pouring the eggs down the wall of the container. Remove "bad" eggs, including white apoptotic, activated, variegated, and stringy eggs using a transfer pipette. If a batch contains more than $\sim 10 \%$ "bad" eggs, discard it.

42. Combine the good batches of eggs in a $2 \mathrm{~L}$ glass beaker and pour off as much liquid as possible into a $4 \mathrm{~L}$ waste beaker.

It is important to move through the HSS and NPE protocols as quickly as possible to achieve active extracts. From dejellying eggs to flash freezing the final extract, the NPE protocol should not take longer than $6 \mathrm{~h}$. It is helpful to start a timer at the point of addition of the Dejelly solution. Approximate timing is indicated at each step in ().

43. (Time: $0 \mathrm{~min}$ ) To dejelly the eggs, add one-third of the Dejelly solution and mix thoroughly with the eggs using a plastic transfer pipette or glass Pasteur pipette. Start a timer that counts up at the moment of Dejelly solution addition. Continue stirring gently for $\sim 3 \mathrm{~min}$. Allow the eggs to settle, pour off the Dejelly solution, add another third of the Dejelly solution, stir for 2 min, and allow the eggs to settle. After once again decanting the Dejelly solution, add the last of the Dejelly solution and stir gently until the $7 \mathrm{~min}$ time point. Decant as much Dejelly solution as possible.

It is essential to thoroughly dejelly the eggs, which is seen by dramatic compaction of the eggs. The solution should become completely clear.

44. (Time: $7 \mathrm{~min}$ ) Rinse the dejellied eggs three times with $0.6 \mathrm{~L}$ of $0.5 \times \mathrm{MMR}$ each time, giving a quick stir and then allowing the eggs to settle. Decant excess MMR before the next addition.

Pour the buffer down the side of the beaker to prevent harming the eggs, which are fragile once dejellied.

45. After decanting the last $0.5 \times$ MMR rinse, wash the eggs three times with $300 \mathrm{~mL}$ ELB-sucrose each time. The eggs are more stable in ELB-sucrose, which allows time to remove any bad or apoptotic eggs. The bad white eggs collect in the center of the beaker after stirring, allowing convenient removal with a plastic transfer pipette.

46. (Time: $20 \mathrm{~min}$ ) Decant as much ELB-sucrose as possible and transfer the eggs into 15-mL Falcon 2059 tubes. Allow the eggs to settle, and aspirate excess buffer. Pack the eggs by centrifugation for $1 \mathrm{~min}$ at $200 \mathrm{~g}$ at room temperature in a swinging-bucket rotor such as IEC Centra CL2, and aspirate excess buffer. Make a second addition of eggs to each tube, adding as many as possible, and repeat the packing centrifugation and excess buffer removal.

A normal yield at this stage is 12 tubes of eggs.

47. After buffer removal, onto the surface of the packed eggs, add $0.5 \mu \mathrm{L}$ of aprotinin/leupeptin stock solution $(10 \mathrm{mg} / \mathrm{mL})$ and $0.5 \mu \mathrm{L}$ of cytochalasin B stock solution $(5 \mathrm{mg} / \mathrm{mL})$ per mL packed eggs. No mixing is necessary as the centrifugation in the next step is sufficient.

48. (Time $40 \mathrm{~min}$ ) Crush the eggs by centrifugation for $20 \mathrm{~min}$ at 20,000g in a Sorvall Lynx 4000 centrifuge and swinging-bucket rotor TH13-6X50 in a centrifuge that is precooled to $4^{\circ} \mathrm{C}$. Although the centrifuge itself is precooled, it is essential to keep the rotors at room temperature 
until the centrifugation starts to ensure the eggs are at room temperature when crushed. This is essential to drive extracts into interphase. After centrifugation, keep the extract on ice.

49. (Time $60 \mathrm{~min}$ ) After centrifugation, transfer the tubes with crushed eggs to an ice bucket. Clean the outside of the tube with 70\% ethanol and then dry the tube with a paper towel. Insert an $18 \mathrm{~g}$ needle about $3 \mathrm{~mm}$ above the mitochondrial layer (Fig. 1B, red arrow). Remove the needle and allow the LSS to drip into a 50-mL conical tube. When the yellow lipids begin to come out, stop collecting and discard the tube. It is important to include the brown layer just below the yellow lipids during collection.

50. Repeat Step 49 for each tube of crushed eggs.

\section{Preparation of HSS (High-Speed Supernatant)}

51. (Time $90 \mathrm{~min}$ ) To the LSS, add $50 \mu \mathrm{g} / \mathrm{mL}$ cycloheximide, $1 \mathrm{~mm}$ DTT, $10 \mu \mathrm{g} / \mathrm{mL}$ aprotinin/ leupeptin, and $5 \mu \mathrm{g} / \mathrm{mL}$ cytochalasin B (final concentrations).

52. Mix by inverting gently 10 times.

53. Transfer LSS to $2.5 \mathrm{~mL}$ thin-walled ultracentrifuge tubes. The rotor should be kept at $4^{\circ} \mathrm{C}$ until use. Centrifuge the extract for $90 \mathrm{~min}$ at $260,000 \mathrm{~g}$ at $2^{\circ} \mathrm{C}$ in a swinging-bucket rotor $(55,000 \mathrm{rpm}$

A
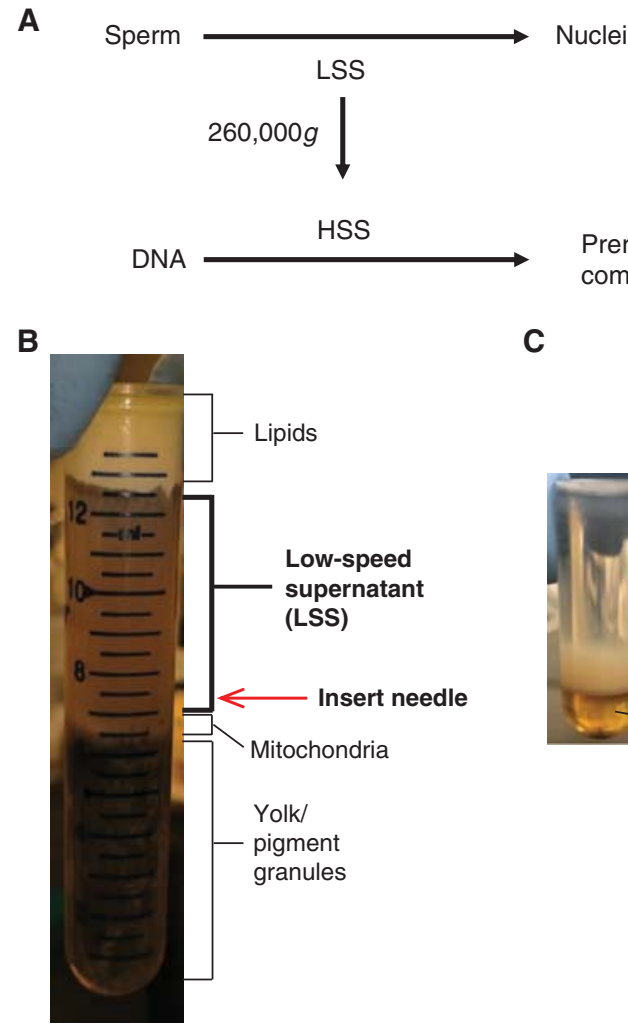

Prereplication
complex

NPE

Nucleus-independent

DNA replication

C

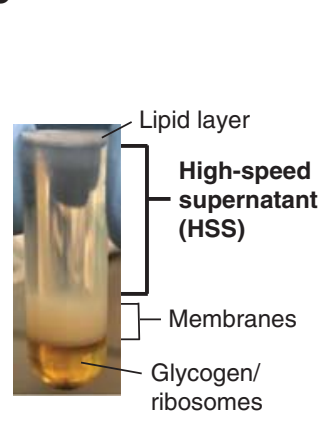

D

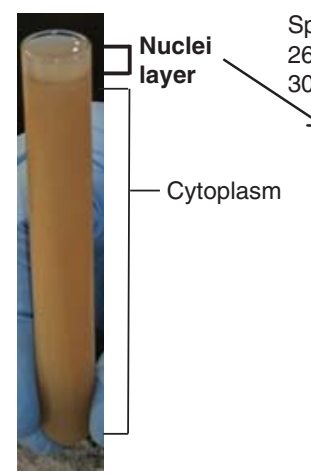

Spin $60,000 \mathrm{~g}$

$30 \mathrm{~min}$
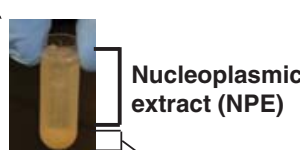

Nuclear envelopes /chromatin

FIGURE 1. Preparation of DNA replication competent extracts from Xenopus eggs. (A) Schematic representation of nucleus-free DNA replication competent extracts, and the nucleus-free DNA replication assay. Addition of sperm to LSS extract allows for nuclei formation, which are harvested to make NPE. LSS is centrifuged at high speed to prepare HSS. For nucleus-free DNA replication, sperm chromatin or plasmid DNA is incubated in HSS to promote the assembly of prereplication complexes (pre-RCs). Addition of NPE after pre-RC assembly converts the pre-RCs to active replication forks, and replication commences. $(B)$ The eggs are crushed through centrifugation to make lowspeed supernatant (LSS) (Step 48). Red arrow indicates the insertion of the needle to extract the LSS. (C) Result of ultracentrifugation of the LSS extract to harvest high-speed supernatant (HSS) (Step 56). (D) Nuclei are collected after incubation of LSS with sperm chromatin. Centrifugation of the nuclei assembly reaction causes the nuclei to float and nucleoplasmic extract (NPE) can be derived from these nuclei through ultracentrifugation (Step 71). 
using Optima Max-E Beckman ultracentrifuge or equivalent and swinging-bucket rotor, such as the TLS-55 Beckman or equivalent).

54. After the centrifugation, remove the top layer of lipids (Fig. 1C) by gently touching the surface with the bulb of a plastic Pasteur pipette, twisting it, and lifting it out. Aspirate the remaining lipids with an ultrathin gel-loading tip.

55. Using a p200 tip cut off a third of the way from the bottom, recover the HSS (Fig. 1C), taking care not to contaminate the preparation with the underlying membrane fraction, and transfer the extract to a new ultracentrifuge tube.

56. (Time $3.25 \mathrm{~h}$ ) Centrifuge the extract again for $30 \mathrm{~min}$ at $260,000 \mathrm{~g}$ at $2^{\circ} \mathrm{C}$.

57. Remove any lipids on the surface by aspiration as before. Harvest the clear HSS layer, being careful to avoid the pellet.

58. Mix the HSS thoroughly with a pipette. Snap-freeze $33 \mu \mathrm{L}$ aliquots in liquid nitrogen. Store aliquots at $-80^{\circ} \mathrm{C}$. HSS is stable for several years at $-80^{\circ} \mathrm{C}$.

\section{Preparation of Nucleoplasmic Extract (NPE)}

59. Begin by making LSS according to the above protocol, but use eggs collected from 20 female frogs and increase the volume of buffers used to dejelly the eggs to 2 L Dejelly solution, 4 L $0.5 \times$ MMR, and 2 L ELB-sucrose.

To achieve maximally active extract, this protocol should be finished in less than $6 \mathrm{~h}$ from the time the eggs are dejellied.

60. To the harvested LSS from Step 50 (usually $35-80 \mathrm{~mL}$ ), add $50 \mu \mathrm{g} / \mathrm{mL}$ cycloheximide, $1 \mathrm{~mm}$ DTT, $10 \mu \mathrm{g} / \mathrm{mL}$ aprotinin/leupeptin, $5 \mu \mathrm{g} / \mathrm{mL}$ cytochalasin $\mathrm{B}$, and $3.3 \mu \mathrm{g} / \mathrm{mL}$ nocodazole (final concentrations). Mix by gentle inversion 15 times.

If nocodazole is omitted, microtubules will bind to the nuclei (Karsenti et al. 1984) and prevent their recovery.

61. (Time: $90 \mathrm{~min}$ ) Transfer the extract to $15 \mathrm{~mL}$ Falcon 2059 tubes and centrifuge for $15 \mathrm{~min}$ at $20,000 \mathrm{~g}$ at $4^{\circ} \mathrm{C}$ in a Sorvall Lynx 4000 centrifuge and swinging-bucket rotor TH13-6X50, with adapters to hold Falcon 2059 15-mL tubes.

62. After the centrifugation, remove the pale-yellow lipid layer by gently touching the surface with the bulb of a plastic transfer pipette, twisting it, and lifting it out. Aspirate remaining lipids with a thin gel-loading tip. Remove as little extract as possible, as the dark brown layer just below the lipid layer will be helpful when harvesting the nuclei later in the protocol.

63. In one continuous, steady movement, decant the extract into a $50 \mathrm{~mL}$ conical tube. Leave behind about $1 \mathrm{~mL}$ of extract per tube to avoid transferring the black particles at the bottom of the tube, which inhibit nuclear assembly.

64. Warm the extract to room temperature by holding it for $5-10 \mathrm{~min}$; this is essential for proper nuclear assembly.

65. (Time: $2 \mathrm{~h}$ ) Add $2 \mathrm{~mm} \mathrm{ATP,} 20 \mathrm{~mm}$ phosphocreatine, and $5 \mu \mathrm{g} / \mathrm{mL}$ creatine phosphokinase (final concentrations). Mix by gently inverting the tubes 12 times.

66. Set up the nuclear assembly reaction by pouring $4.5 \mathrm{~mL}$ of extract into a new $50 \mathrm{~mL}$ conical tube. Remove $1 \mathrm{~mL}$ of the $4.5 \mathrm{~mL}$ with a p1000 and mix it with a $90 \mu \mathrm{L}$ aliquot of $220,000 / \mu \mathrm{L}$ demembranated sperm chromatin by pipetting up and down 15 times. Return the extract-sperm mixture to the $50 \mathrm{~mL}$ conical tube. Pour another $4.5 \mathrm{~mL}$ of extract into the same $50 \mathrm{~mL}$ conical tube and repeat the procedure of mixing $1 \mathrm{~mL}$ extract with an aliquot of sperm chromatin. Repeat this procedure until the $50 \mathrm{~mL}$ conical tube is filled with extract-sperm mixture or until extract is used up. If there are more than $50 \mathrm{~mL}$ of extract, continue the procedure with a second $50 \mathrm{~mL}$ tube. If a second tube is used, equalize the volume of nuclear assembly reaction in both tubes. 
67. (Time: $2.5 \mathrm{~h}$ ) Mix the nuclear assembly reaction by inverting it gently 10 times and lay the tube on its side on the benchtop.

68. Incubate the nuclear assembly reaction for roughly $80 \mathrm{~min}$ from the time of the addition of the first sperm chromatin. Invert the tube a few times every $10 \mathrm{~min}$, gently but thoroughly.

Nuclear assembly should not exceed $90 \mathrm{~min}$ as the nuclei will eventually undergo apoptosis.

69. Check the progress of nuclear assembly at $60 \mathrm{~min}$ by pipetting $1 \mu \mathrm{L}$ of the assembly reaction and $1 \mu \mathrm{L}$ of Hoechst staining solution onto a microscope slide. Mix by gentle stirring with a pipette tip and cover the mixture with a microscope coverslip. Examine the nuclei with a fluorescence microscope using the DAPI channel. Nuclei should be $\sim 25-30 \mu \mathrm{m}$ in diameter. If nuclei have not reached this diameter, keep incubating until nuclei reach $25-30 \mu \mathrm{m}$ (or more), but not longer than $90 \mathrm{~min}$.

See Troubleshooting.

70. At the 70-80 min time point, pour the assembly reaction into $13 \times 100 \mathrm{~mm}$ glass test tubes placed inside a $15 \mathrm{~mL}$ Falcon 2059 tube with the void volume filled with water to prevent the glass tube from cracking during centrifugation. From now on, keep the extract on ice.

71. (Time: $4 \mathrm{~h}$ ) Centrifuge the extract for $2.5 \mathrm{~min}$ at $20,000 \mathrm{~g}$ at $4^{\circ} \mathrm{C}$ in a Sorvall Lynx 4000 centrifuge and swinging-bucket rotor TH13-6X50 or equivalent, with adapters to hold Falcon 2059 15-mL tubes.

Nuclei will float to the top of the tube during centrifugation creating a clear/white viscous layer about 4-6 $\mathrm{mm}$ thick (Fig. 1D). This layer is separated from the golden cytoplasmic layer by a thick brown layer that is more viscous than the nuclei layer. The brown layer helps prevent contamination of the nuclei with the underlying LSS.

See Troubleshooting.

72. Harvest nuclei using a p200 pipette with the tip cut a third of the way from the bottom. Hold the pipette at a $45^{\circ}$ angle to more easily collect the viscous nuclei while avoiding the LSS. It is helpful to recover the nuclei by collecting along the wall of the tube while slowly rotating the tube, being careful not to disrupt the interface separating the nuclei from the cytoplasmic layer underneath. Transfer the nuclei into a thick-walled ultracentrifuge tube (or a thin-walled tube if you have more than $1.5 \mathrm{~mL}$ of nuclei). After no more nuclei can be removed around the edge of the tube, collect from the center of the tube while still slowly rotating. It is important to be patient and collect as much of the nuclei as possible.

73. Centrifuge the nuclei for $30 \mathrm{~min}$ at $260,000 \mathrm{~g}$ at $2^{\circ} \mathrm{C}$ in an ultracentrifuge, such as an Optima MaxE ultracentrifuge (Beckman) or equivalent using a swinging-bucket rotor, such as the TLS-55 (Beckman) or equivalent. The tubes should be kept on ice after the centrifugation.

74. Aspirate and discard the white lipid layer (Fig. 1D) with a fine gel-loading tip, taking care not to lose much extract.

75. Harvest the clear nucleoplasmic extract with a p200 pipettor, being careful not to contaminate the extract with the insoluble pellet, which consists of nuclear envelopes and chromatin (Fig. 1D).

76. After mixing the harvested nucleoplasmic extract by pipetting up and down, snap-freeze the NPE in $20 \mu \mathrm{L}$ aliquots with liquid nitrogen. Expected yield can vary from 100 to $2 \mathrm{~mL}$. The aliquots are stored at $-80^{\circ} \mathrm{C}$ and are stable for several years.

See Troubleshooting.

Problem (Step 69): Nuclei grow but then disappear completely.

Solution: The extract underwent apoptosis due to contamination with and lysis of mitochondria. 
Problem (Step 69): No nuclei grew as visualized by epifluorescence microscopy.

Solution: One possible reason is poor quality sperm. We have found that it is critical to completely remove the Triton X-100 from the sperm chromatin. Residual Triton prevents the formation of nuclei during the assembly reaction.

Problem (Step 71): Only small nuclear layers form.

Solution: There are several possible factors that can be considered in the next NPE preparation.

- The sperm are of poor quality or the concentration is too low or too high.

- Too many mitochondria may have been collected from the respun LSS (Step 63), which can impede growth.

- The extract must be allowed to come to room temperature (Step 64) before the nuclear assembly reaction can begin. Starting the assembly too quickly will slow the growth of the nuclei.

Problem (Step 71): Nuclei grow but no nuclear layer forms to allow harvesting.

Solution: It is possible that nocodozole was left out. Microtubule growth prevents the nuclei from floating and forming a layer.

Problem (Step 76): There are many steps that can affect the volume and the quality of an NPE preparation. Below we outline several pitfalls of the NPE preparation, and how to avoid them.

Solutions: Consider the following.

- It is important to move through the procedures as quickly as possible. The NPE preparation should not exceed $6 \mathrm{~h}$ to maintain the activity of the extract.

- It is also important that the centrifuge rotor is at room temperature for the egg-crushing step.

- The egg quantity and quality are major factors in determining the quantity and quality of an NPE preparation. It is important to remove as many of the apoptotic eggs as possible prior to packing of the eggs.

- Avoid mitochondrial contamination during the NPE preparation, which starts with the harvesting of the LSS (Step 49). High levels of mitochondrial contamination can lead to nuclear membrane fragmentation during nuclear assembly by the release of cytochrome C (Kluck et al. 1997). This will prevent the formation of the NPE layer.

The extracts made using these protocols allow for in vitro nucleus-free replication of fully chromatinized DNA templates including small plasmids, which is outlined in Figure 1A (Walter et al. 1998; Arias and Walter 2004). The high-speed supernatant (HSS) allows DNA licensing by loading of prereplicative complexes (pre-RCs) randomly on the DNA template. Demembranated sperm chromatin is used to assemble nuclei that are harvested to make concentrated nucleoplasmic extract (NPE) that drives the initiation of DNA replication by supplying high concentrations of Cdk2-Cyclin E (Prokhorova et al. 2003). Xenopus egg extracts contain the entirety of the soluble egg proteome including all of the DNA replication and repair machinery. This extract system has been successfully used to study many aspects of DNA metabolism including DNA replication, mismatch repair (Kawasoe et al. 2016), replication-coupled DNA interstrand cross-link repair (Räschle et al. 2008), replicationcoupled DNA-protein cross-link repair (Duxin et al. 2014), DNA replication termination (Dewar et al. 2015), as well as many other processes (Lebofsky et al. 2009; Knipscheer et al. 2012). How 
J. Sparks and J.C. Walter

Xenopus extracts and the NPE system have contributed to our detailed understanding of DNA replication and repair is reviewed elsewhere (Hoogenboom et al. 2017).

\section{RELATED INFORMATION}

In our experience, almost any preparation of HSS is sufficient to support DNA licensing. However, NPE preparations can vary significantly in volume and in their ability to initiate DNA replication. Highly active NPE will complete replication of $2.5 \mathrm{ng} / \mu \mathrm{L}$ (final concentration) of supercoiled plasmid DNA in less than 15 min. This is a benchmark against which new NPE preparations should be compared.

\section{RECIPES}

Buffer X $(10 \times)$

\begin{tabular}{lcr} 
Reagent & Quantity $(20 \mathrm{~mL})$ & Final concentration \\
\hline $\mathrm{HEPES}-\mathrm{KOH}(1 \mathrm{M}, \mathrm{pH} 7.4-7.6)$ & $2 \mathrm{~mL}$ & $100 \mathrm{~mm}$ \\
$\mathrm{KCl}(1 \mathrm{M})$ & $1.6 \mathrm{~mL}$ & $80 \mathrm{~mm}$ \\
$\mathrm{NaCl}(5 \mathrm{M})$ & $0.6 \mathrm{~mL}$ & $150 \mathrm{~mm}$ \\
$\mathrm{MgCl}_{2}(1 \mathrm{M})$ & $1 \mathrm{~mL}$ & $50 \mathrm{~mm}$ \\
$\mathrm{EDTA}(0.5 \mathrm{M})$ & $0.4 \mathrm{~mL}$ & $10 \mathrm{~mm}$ \\
$\mathrm{dH}_{2} \mathrm{O}$ & $14.4 \mathrm{~mL}$ &
\end{tabular}

Make fresh on the day of extract preparation.

\section{Creatine Phosphokinase Solution}

Dissolve creatine phosphokinase ( $5 \mathrm{mg} / \mathrm{mL}$; Sigma-Aldrich C3755) in $50 \mathrm{~mm} \mathrm{NaCl}, 50 \%$ glycerol, and $10 \mathrm{~mm}$ HEPES-KOH (pH 7.5). Store for $2-6 \mathrm{mo}$ at $-20^{\circ} \mathrm{C}$. Do not freeze at $-80^{\circ} \mathrm{C}$.

Dejelly Solution

\begin{tabular}{lll} 
Reagent & Quantity & Final concentration \\
\hline
\end{tabular}

L-cysteine-HCl (Fisher ICN10144601) $\quad 44 \mathrm{~g} \quad 2.2 \%$

Use $\mathrm{dH}_{2} \mathrm{O}$ to bring volume to $2 \mathrm{~L}$, and adjust $\mathrm{pH}$ to 7.7 with $10 \mathrm{M} \mathrm{NaOH}$. Make fresh on the day of extract preparation.

Egg Lysis Buffer (ELB-Sucrose)

\begin{tabular}{lrr} 
Reagent & Quantity (1 L) & Final concentration \\
\hline Sucrose & $85.6 \mathrm{~g}$ & $0.25 \mathrm{M}$ \\
ELB salts $(10 \times)<\mathrm{R}>$ & $100 \mathrm{~mL}$ & $1 \times$ \\
DTT (Bio-Rad 161-0611) & $154 \mathrm{mg}$ & $0.154 \mathrm{mg} / \mathrm{mL}$ \\
Cycloheximide (Calbiochem 239763) & $50 \mathrm{mg}$ & $0.05 \mathrm{mg} / \mathrm{mL}$
\end{tabular}

Use ultrapure sucrose ( $\geq 99 \%$; Invitrogen 15503-022). Adjust volume to $1 \mathrm{~L}$ with $\mathrm{dH}_{2} \mathrm{O}$. Make fresh on the day of extract preparation. 
Egg Lysis Buffer Salts (ELB Salts; 10×)

\begin{tabular}{lcc} 
Reagent & Quantity $(500 \mathrm{~mL})$ & Final concentration \\
\hline $\mathrm{MgCl}_{2}(1 \mathrm{M})$ & $12.5 \mathrm{~mL}$ & $25 \mathrm{~mm}$ \\
$\mathrm{KCl}$ & $18.64 \mathrm{~g}$ & $500 \mathrm{~mm}$ \\
$\mathrm{HEPES}$ & $11.91 \mathrm{~g}$ & $100 \mathrm{~mm}$
\end{tabular}

Add water to a volume of $500 \mathrm{~mL}$. Adjust $\mathrm{pH}$ to 7.7 with $\mathrm{KOH}$. Filter-sterilize, and store at $4^{\circ} \mathrm{C}$.

\section{Hoechst Stock Solution}

\begin{tabular}{lcr} 
Reagent & Quantity $(\sim 400 \mu \mathrm{L})$ & Final concentration \\
\hline Sucrose $(1 \mathrm{M})$ & $80 \mu \mathrm{L}$ & $200 \mathrm{~mm}$ \\
HEPES-KOH $(1 \mathrm{M}, \mathrm{pH} 7.6)$ & $4 \mu \mathrm{L}$ & $10 \mathrm{mM}$ \\
Formaldehyde $(37 \%)$ & $80 \mu \mathrm{L}$ & $7.4 \%$ \\
Hoechst $(1.0 \mathrm{mg} / \mathrm{mL})$ & $3.2 \mu \mathrm{L}$ & $8 \mu \mathrm{g} / \mathrm{mL}$ \\
$\mathrm{H}_{2} \mathrm{O}$ & $232 \mu \mathrm{L}$ &
\end{tabular}

Dilute $10 \mathrm{mg} / \mathrm{mL}$ stock of Hoechst in water prior to use above. Store final solution at room temperature protected from light.

Marc's Modified Ringer's (MMR) for Xenopus (20x)

\begin{tabular}{lrr} 
Reagent & Quantity $(1 \mathrm{~L})$ & Final concentration \\
\hline $\mathrm{NaCl}$ & $116.8 \mathrm{~g}$ & $2 \mathrm{M}$ \\
$\mathrm{KCl}$ & $3 \mathrm{~g}$ & $40 \mathrm{mM}$ \\
$\mathrm{MgSO}_{4} \cdot 7 \mathrm{H}_{2} \mathrm{O}$ & $2.4 \mathrm{~g}$ & $10 \mathrm{mM}$ \\
$\mathrm{CaCl}_{2} \cdot 2 \mathrm{H}_{2} \mathrm{O}$ & $7.34 \mathrm{~g}$ & $50 \mathrm{mM}$ \\
EDTA & $0.58 \mathrm{~g}$ & $2 \mathrm{mM}$ \\
$\mathrm{HEPES}$ & $23.8 \mathrm{~g}$ & $100 \mathrm{~mm}$
\end{tabular}

Add water to $1 \mathrm{~L}$. Adjust $\mathrm{pH}$ of solution to 7.8 with $\mathrm{KOH}$. Filter-sterilize, and store at $4^{\circ} \mathrm{C}$.

Sucrose Buffers for Preparation of Demembranated Sperm Chromatin

\begin{tabular}{|c|c|c|c|c|c|}
\hline Reagent & $\begin{array}{c}\text { Buffer \#1 } \\
(0.2 \mathrm{M} \\
\text { sucrose })\end{array}$ & $\begin{array}{c}\text { Buffer \#2 } \\
(2.3 \mathrm{M} \\
\text { sucrose })\end{array}$ & $\begin{array}{c}\text { Buffer \#3 } \\
(2.5 \mathrm{M} \\
\text { sucrose })\end{array}$ & $\begin{array}{c}\text { Buffer \#4 } \\
(2.0 \mathrm{M} \\
\text { sucrose })\end{array}$ & $\begin{array}{c}\text { Buffer \#5 } \\
(0.5 \mathrm{M} \\
\text { sucrose })\end{array}$ \\
\hline Buffer X $(10 \times)<$ R $>$ & $10 \mathrm{~mL}$ & $1 \mathrm{~mL}$ & $1 \mathrm{~mL}$ & $1 \mathrm{~mL}$ & $1 \mathrm{~mL}$ \\
\hline Sucrose & $6.84 \mathrm{~g}$ & $7.87 \mathrm{~g}$ & $8.56 \mathrm{~g}$ & $6.84 \mathrm{~g}$ & 1.71 \\
\hline $\begin{array}{l}\mathrm{BSA} \\
\mathrm{H}_{2} \mathrm{O}\end{array}$ & to $100 \mathrm{~mL}$ & to $10 \mathrm{~mL}$ & to $10 \mathrm{~mL}$ & to $10 \mathrm{~mL}$ & $\begin{array}{l}300 \mathrm{mg} \\
\text { to } 10 \mathrm{~mL}\end{array}$ \\
\hline
\end{tabular}

For Buffer \#6 (0.2 M sucrose), add $300 \mathrm{mg}$ of BSA to $10 \mathrm{~mL}$ of Buffer \#1. Use BSA from Sigma-Aldrich (A7906). Do not use other types of BSA, as they can ruin the sperm preparation. For all buffers, use ultrapure sucrose ( $\geq 99 \%$; Invitrogen 15503-022). For Buffers \#5 and \#6 and for $5 \mathrm{~mL}$ of Buffer \#1, include $10 \mu \mathrm{g} / \mathrm{mL}$ aprotinin (Roche 11583794001), $10 \mu \mathrm{g} / \mathrm{mL}$ leupeptin (Roche 11529048001), and 1 mM DTT (Bio-Rad 161-0611). Make all buffers fresh on the day of extract preparation. 


\section{REFERENCES}

Arias EE, Walter JC. 2004. Initiation of DNA replication in Xenopus egg extracts. Front Biosci 1: 3029-3045.

Dewar JM, Budzowska M, Walter JC. 2015. The mechanism of DNA replication termination in vertebrates. Nature 525: 345-350.

Duxin JP, Dewar JM, Yardimci H, Walter JC. 2014. Repair of a DNA-protein crosslink by replication-coupled proteolysis. Cell 159: 346-357.

Hoogenboom WS, Klein Douwel D, Knipscheer P. 2017. Xenopus egg extract: A powerful tool to study genome maintenance mechanisms. Dev Biol 428: 300-309.

Karsenti E, Newport J, Hubble R, Kirschnre M. 1984. Interconversion of metaphase and interphase microtubule arrays, as studied by the injection of centrosomes and nuclei into Xenopus eggs. J Cell Biol 98: $1730-1745$.

Kawasoe Y, Tsurimoto T, Nakagawa T, Masukata H, Takahashi TS. 2016. MutS $\alpha$ maintains the mismatch repair capability by inhibiting PCNA unloading. Elife 5: e15155.

Kluck RM, Bossy-Wetzel E, Green DR, Newmeyer DD. 1997. The release of cytochrome $\mathrm{c}$ from mitochondria: A primary site for Bcl-2 regulation of apoptosis. Science 275: 1132-1136.
Knipscheer P, Räschle M, Schärer OD, Walter JC. 2012. Replication-coupled DNA interstrand cross-link repair in Xenopus egg extracts. Methods Mol Biol 920: 221-243.

Lebofsky R, Takahashi T, Walter JC. 2009. DNA replication in nucleus-free Xenopus egg extracts. Methods Mol Biol 521: 229-252.

Lohka MJ, Hayes MK, Maller JL. 1988. Purification of maturation-promoting factor, an intracellular regulator of early mitotic events. Proc Natl Acad Sci 85: 3009-3013.

Murray AW, Solomon MJ, Kirschner MW. 1989. The role of cyclin synthesis and degradation in the control of maturation promoting factor activity. Nature 339: 280-286.

Prokhorova TA, Mowrer K, Gilbert CH, Walter JC. 2003. DNA replication of mitotic chromatin in Xenopus egg extracts. Proc Natl Acad Sci 100: 13241-13246.

Räschle M, Knipscheer P, Enoiu M, Angelov T, Sun J, Griffith JD, Ellenberger TE, Schärer OD, Walter JC. 2008. Mechanism of replicationcoupled DNA interstrand crosslink repair. Cell 134: 969-980.

Walter J, Sun L, Newport J. 1998. Regulated chromosomal DNA replication in the absence of a nucleus. Mol Cell 1: 519-529. 


\section{Extracts for Analysis of DNA Replication in a Nucleus-Free System}

Justin Sparks and Johannes C. Walter

Cold Spring Harb Protoc; doi: 10.1101/pdb.prot097154 originally published online May 16, 2018

\begin{tabular}{rc}
$\begin{array}{r}\text { Email Alerting } \\
\text { Service }\end{array}$ & Receive free email alerts when new articles cite this article - click here. \\
\hline $\begin{array}{c}\text { Subject } \\
\text { Categories }\end{array}$ & $\begin{array}{c}\text { Browse articles on similar topics from Cold Spring Harbor Protocols. } \\
\text { Cell Biology, general (1382 articles) } \\
\text { Preparation of Cellular and Subcellular Extracts (104 articles) } \\
\text { Subcellular Fractionation (88 articles) } \\
\text { Xenopus (210 articles) }\end{array}$ \\
\hline
\end{tabular}

